SHS Web of Conferences 7, 02002 (2014)

DOI: $10.1051 /$ shsconf / 20140702002

C Owned by the authors, published by EDP Sciences, 2014

\title{
A Brief Analysis of Large Classroom's English Teaching Management Skills
}

\author{
Zhong Weixuan \\ Institute of Foreign Languages and Literature, Hechi University, 546300 Yizhou Guangxi, China
}

\begin{abstract}
Classroom is the basic place of teaching, where intertwined with a variety of teaching factors, and all these factors forms various kinds of connections. Scientific and effective class teaching management is the necessary and powerful measure of improving the teaching quality. Effective English teaching management skills are parts of the elements of successful large classroom teaching. Under the new educational situation, how to organize, regulate, manage large classrooms in order to train the students' English proficiency within certain time, which is very important to improve English classes management efficiency and teaching quality.
\end{abstract}

Keywords. class teaching management; large class; English teaching management

Classroom is the product of class teaching system, where intertwined with a variety of teaching factors, and all these factors form various kinds of connections. The main function of classroom management is to coordinate, control, and integrate these teaching factors and their relationship, so as to form an ordered whole to ensure teaching activities go smoothly. Similarly, it is also the necessary and powerful measure of ensuring smooth and efficient completion of teaching work. That is teachers establish harmonious environment through effective teaching management, so as to ensure smooth implementation of language skills and teaching. However, in recent years, primary and secondary English classroom size gradually expanded, and appeared big classrooms even large classrooms. It is difficult to manage and control large English classroom, which brought serious impact on improving the quality of English teaching. Therefore, under the new situation, in order to complete the training of the students' English language sills within certain time, how to manage, organize, and control large classroom, has become a major task for most teachers.

\section{Modern classroom management and large classroom teaching}

\subsection{The features of modern classroom management}

Teaching management has a long history. After the mid- $20^{\text {th }}$ century, teaching management, as a specific field draw increasing attention, and gradually developed into a compelling emerging international academic field of study. Its appearance further enriched and developed the connotation of teaching management, and promoted the transformation of classroom concepts and education. Since the 1960 s, countries have been extensively engaged in classroom management reform attempts, such as class structure improvement, teaching efficiency improvement and so on. Therefore, teaching 
management had lots of new changes, and formed new class management by degrees. The conventional class was more inclined to behavioral control and stylized problem solving, focused on obeying rules and regulations, and was given more attention to class discipline and prescriptive. Comparatively speaking, new class is more inclined to motivate behavior and creative problem solving, focuses on teachers' encouragement and students' participation, and is given more attention to the growth and flexibility of class. Class management shows a transition from rigidity to flexibility. ${ }^{[1]}$

\subsection{The features of modern English teaching}

English teaching is a diverse, complex activity of teaching and learning. Modern English teaching, which is goal-oriented, student-centered, and language use-targeted, is reforming and developing forward three aspects. Firstly, create separately special environment, so that students can get more chances for individual practice. Secondly, relax control, adopting various forms of activities to provide psychological conditions for students to practice freely. Thirdly, try to get the integration of language practice and simulated communication. Therefore, the relationship between teachers and students in English class has gone on the fundamental change. Teaching has increasingly involved in threedimensional figures, task, and individual. Teaching is turning a shift from static to dynamic flow, which makes it more difficult to organize, manage, and control. ${ }^{[2]}$

\subsection{Class size and English class management}

There are varieties of factors that affected English teaching management, and of all, class size is an important one. Generally speaking, teachers in the classroom perspective cover no more than 25 students, so the more the number of students is; the more difficulties of the classroom management are. Teaching effect is just like magnetic or electric field, the larger classroom, the weaker teaching effect. The less classroom control, the more serious phenomenon of the students "fake participation". Since the new features and the contradiction of the large classroom have appeared, disorder, hard to control, lack of language training, etc. could always occur. Even if the implementation of the communicative approach and task-based teaching, teachers will also feel anxious, inadequate, inefficient, and ineffective, unless adopt effective management. Therefore, it is very important to master effective management of large classroom, for improving the English classroom management efficiency and the quality of teaching.

\section{Effective teaching strategies of large English classroom}

\subsection{Establish the scientific educational concept is the premise of large classroom teaching management}

Marx once says, "in the future, the ultimate goal and mission is to achieve everyone's free, harmonious and comprehensive development." The current phenomenon of large classroom brings huge impact on achieving the ultimate goal and mission, and challenges everyone's free, and harmonious and comprehensive development. Towards this objective, teachers cannot stay the management to such a level that maintaining discipline, rectification order, simply imparting knowledge, etc. Teachers should keep pace with the times, master the modern classroom management skills, and establish a scientific and advanced educational concept.

Highlight the dominant position of students. Language is a communicative tool, and the biggest characteristic of English teaching is to cultivate students' communicative competence, which cannot be separate from practice. Therefore, teachers should break the traditional mode of teaching, and correctly handle the relationship between teaching and learning. Organizing the "student-centered" teaching activities, trying to mobilize all the students to actively participate in the education process, move, speak, and develop their language proficiency. ${ }^{[3]}$ During this process, helping them find their own potential, build self- confidence, and cultivate their spirit of cooperation. Teaching management 
is not only help the students get linguistic knowledge and language skills, but also learn happily, skillfully, and efficiently.

Change the teachers' roles. Nowadays, students' subjective status is increasingly emphasized, some teachers are confused of this new relationship between teachers and students, especially when facing more and more active students. Then, how to solve this problem, how to control, and to what extent cannot hamper students' development? Behind this confusion is the result of the changing from the conventionally educational concept to the new one. Although the students play subjective roles, the dominant roles of the teachers in the teaching process are irreplaceable. Based on language acquisition rules, teachers should adopt scientific and orderly training methods, and strengthen the organization and regulation of the classroom. Through changing roles, students treat classroom as steps of the English mountain, and teachers as cooperator, director, and partner. It is obvious that new teacher-student relationship calls for higher requirements of teachers' quality and ability, doesn't ignore the role of English teachers.

Establish a new classroom discipline. Schools need to have some discipline, so it is with students, and large classroom cannot work without discipline. But too much emphasis on discipline will inevitably stifle students' lively personality and nature, and bound students' thinking space and imagination. In classroom, the more important is individuality flying, active and deep thinking, and inspiring wisdom. The essence of language teaching is "communication", and the specific embodiments of communication are many concrete and colorful activities. Through visual, listening, speaking, playing, singing, painting, travelling, reading, writing, translating and other interesting activities, classroom provide students sufficient amount of language materials, and plenty of training opportunities. Classroom may be filled with joy, even a little noisy. Teachers don't need to worry about it, as long as the noisy is because of study English. In order to improve the efficiency of large classroom, facing the exciting atmosphere, what the teachers consider is how to control and direct with modern concept to change noise into harmony.

\subsection{Variety of teaching method, self-learning and self-management skills are the basis for optimizing management of large classroom}

Give a man a fish and you feed him for a day, but teach a man to fish and you feed him for a lifetime, which fully demonstrates the importance of teaching methods. In large classroom teaching process, students' dependence on teachers cannot be reduced, until they are taught how to learn. Only when the students get some self-learning ability under the guidance of teachers, can they learn by themselves and improve the ability of obtaining knowledge. Meanwhile, with the increasing self-learning ability, students can master themselves, and the requirements for teachers getting smaller and smaller. Thus, the large classroom will be able to meet individual needs, and outstanding student-centered principle to effectively overcome the disadvantages. ${ }^{[4]}$

Establish a harmonious relationship between teachers and students to form interpersonal classroom management mode. Classroom management mode is the unique and relatively stable form and style of classroom management that is gradually formed during the long-term classroom teaching practice. It includes authoritative mode, laissez- faire mode, taught mode, interpersonal mode, behavior modified mode etc. Of all, interpersonal mode is more in line with the characteristic of English teaching management mode. In large classroom, putting new teaching concept of "facing to all the students" and "student-centered" into effort, the conventional relationships of "teachers' dignity" and "teacherrighteousness" must be abandoned. Establishing the equal and harmonious new teacher- student relations, and promoting constructive classroom atmosphere, are favorable toward the formation of language learning interpersonal style of class management mode. Teachers should play the controlling, serving and directing roles, and democratically exchange and cooperate with students to complete the task in teaching activities. Creating a free, creative and selective language learning environment, meet students' personal, emotional, attitude, and intention needs. Then, the teaching order of large class will get better, and the teaching effectiveness and efficiency will be greatly improved, which is called" trust your master, follow his way". Establishing a harmonious relationship between teachers and 
students is not just the morality issue, more importantly, is related to the quality of English teaching large classrooms of problems. Though it doesn't belong to the scope of English language teaching, its effect cannot be underestimated on large English class.

Teaching students according to their aptitude, implements the lamination teaching. Zhu Xi, an educationalist of the Song Dynasty, says," Sages teach according to their aptitude, small to small achievements, big to big achievements, no disposable people". Difficulties faced by large English classrooms are the number of students is big, and the students' sources are complex. Students have big differences in gender, achievement, ability, character, and cultural background. If handled improperly, would easily cause more and more people losing motivation and interest in learning, and increasing individual differences. Therefore, to all the students, in teaching focusing on differences, varies with individual, guide them according to the circumstances to let them develop their talent, promote advantages and abolish disadvantages. Based on students' differences, the lamination requirements go through all aspects of classroom, which is including lamination in teaching goals, teaching links, teaching content, teaching organization, teaching method, training, work design, test, tutoring, classroom management, etc., achieving the organic combination of lamination teaching and management. Breaking the negative situation caused by traditional teaching, in order to meet the requirements of students at different levels, to improve the overall efficiency of the classroom.

Using the "scale" effect of large classroom, develop the cooperative learning capacity. Large classroom English teaching practice shows that large classrooms can not only establish a good learning atmosphere, but also can take advantage of the scale of large classroom, and achieving satisfactory teaching effect. Classroom competition exists everywhere, and if done properly, this competition can be transformed into a powerful force to stimulate students' desire for knowledge. It is proved that group work as the main form of cooperative learning is a good teaching organizational form in large English classroom teaching. It enables more students directly involved in the activities at the same time, and there are more opportunities to practice freely. It could reduce English learners anxiety when participate in communicative activities, providing an interactive activity patterns and creating a good emotional atmosphere, so as to play more autonomy. Pica (1994) pointed out that group activities can effectively help communication in the classroom than based on the teachers' fixed classroom activities. Group activities allow students to use the language in a broader range of social and interpersonal functions. ${ }^{[5]}$ It can be said that cooperative learning activities solve the conflicts between the more number of students and less practice time, which make the English class teaching speed relaxation, dynamic and static in turn, diverse activities, and effective use of economies of scale in large classrooms.

\subsection{Improving the organization and control ability of English Teachers is the key to optimizing the management of large classrooms}

Emphasize on the change of teaching pace. In classroom teaching process, the form of various components to a certain sequence of regularly alternating in time is classroom teaching pace. Practice shows that good teaching pace can put students into teaching the realm of beauty, which would help improve the quality of teaching. English teaching is an art, which has its own unique pace, especially in large classroom. It is difficult to obtain sufficient students' various sensory perception, and language training is difficult to work, if teachers blindly fast-paced just because of large classroom. On the contrary, if pace is too slow, students would distract, getting visual and auditory fatigue, and resulting in a variety of lost anxiety. Therefore, in large classroom teaching process, teachers should strive to grasp the changes of teaching of pace, and implement the principles of more information, high density, and fast-paced. Try to make the language practice speed changed, movement alternated, density spaced, undulating waves, and relaxation scattered. Promote concentrate attention, and give response positively and rapidly. Increasing the density and frequency of language training, enhance the teaching of artistic infectious.

Establish the necessary programs and practices of English teaching. Classroom rules are the variety of behavior norms both teachers and students should obey. It is an indispensable condition for 
the formation of good teaching order and the basis for effective teaching. In large classroom teaching, if there is no set of effective classroom procedures and practices, it is impossible to organize the teaching activities of dozens of lively children with different characters in an orderly manner. Therefore, according to the features of the English teaching, teachers should formulate regulations and instructions in different links and phases. If the students understand the classroom expressions, they will know what can do, and what is not allowed to do. Different instructions calls for different task, through training, making habit, forming student classroom behavior norms and strictly supervise the implementation, and then gradually internalized as conscious behavior, so as to avoid disorder, and improve the efficiency of classroom management.

Scientific evaluation, stimulate interest and motivation for learning. Large classroom is a large group evaluation for large classroom should follow a general principle, "Not One Less", that is pertinently evaluate each student, fully motivate every one, no student left behind. Traditional teaching evaluation was usually summative, and the "success" as the only measure of students. Teachers accustomed to score queuing to compare students' success, resulting in only a small number of students getting a high score or good ranking, but most students will gradually lose confidence in learning. Through cooperative learning in large classrooms, the competition between individuals becomes a competition teams, pursuing "Not everyone succeed, but everyone get ahead" as a realm of teaching. Try to get a dynamic evaluation process, multi-level evaluation criteria, and diversified evaluation content, forming a pattern of "group members cooperate, groups compete", which move the gravity from individuals competition to cooperation. It truly realizes the evaluation shift from summative to formative to stimulate each student's interest in learning.

\section{Conclusion}

Teaching management, integrates science and art, is a creative work. It is of great importance to learn and pay much attention to classroom management for improving the quality of classroom teaching. Large English classroom is a systematic project. Though it's just a result of certain social historical period, it has its own rules to follow. Every teacher should notice the special rules of large classroom, and know pedagogic knowledge and psychology. Learn to use classroom management skills, learn from each other, in-depth practice and explore the law, and try to find solutions to problems from work. Continuously improve the ability of classroom management to make English classrooms more efficient and meaningful.

\section{References}

1. Zhang Zhengdong, Huang Taiquan, Bilingual English Teaching Course[M]. Beijing: Science Press, 2003.

2. Zhang Zhengdong, New Theory of Language Teaching Skills [M]. Beijing: Science Press, 2001.

3. Yang Lianrui, Modern English Teaching [M]. Jinan: Shandong University Press, 2003.

4. Yang Ping, Primary and Secondary School Teaching[M] Haerbin: Heilongjiang Science and Technology Press, 2002.

5. Tang Xiaojie. Evaluate the Effectiveness of Classroom Teaching and Learning [M]. Nanning: Guangxi Education Press, 2003. 